\title{
Influence of HHO Gas Addition on Combustion, Performance and Emission Characteristics of a CI Engine Fuelled with Used Cooking Oil Bio Fuel Blends
}

\author{
Govindhan SEKAR*, Janakiram GANESH MURALI**, Palanisamy \\ SHANMUGHASUNDARAM*** \\ *Department of Mechanical Engineering, Annapoorana Engineering College, Salem-636308, India, \\ E-mail: sekarsrmvec@gmail.com \\ **Department of Mechanical Engineering, Karpagam College of Engineering, Coimbatore-641032, India, \\ E-mail: ganeshmurali_973@yahoo.com \\ ***Department of Automobile Engineering, Karpagam Academy of Higher Education, Coimbatore-641021, India, \\ E-mail: sunramlec@rediffmail.com \\ cross ref $h$ ttp://dx.doi.org/10.5755/j02.mech.27377
}

\section{Introduction}

In today's world, alternative energy sources are receiving more attention particularly bio fuels which are extracted from plant oils in order to meet the increasing energy demand. Both edible and non-edible oils-based bio fuels are considered as viable renewable and environmentally friendly sources for CI engines. Chen and Wang [1] studied about the extraction of bio fuels from the waste cooking oil. They focused on hydro-processing of oil into alkanes, which can be used as a blend stock for aviation fuel after further cracking and isomerising. SenthurPrabu et al. [2] investigated the performance and emission of CI engine operated with cooking oil bio-diesel. It is reported that engine operated with B30+n-butanol blend emits $37 \%$ less $\mathrm{CO}$ emission and $9 \%$ higher NOx emission compared to diesel fuel. Attia and Hassaneen [3] studied the effect of biodiesel blend extracted from waste cooking oil on CI engine performance. It is concluded that the in-cylinder peak pressure depends on the load and the biodiesel blending ratio. Rizwanul Fattah et al. [4] investigated the impact of antioxidant on the performance and emission characteristics of a CI engine operated with palm biodiesel blends. It is reported that the antioxidants reduced NOx by $12 \%$ compared to B20. Chaurasiya et al. [5] analyzed the characteristics of CI engine operated with diesel blended with raw jatropha, soybean and cooking oils. It is reported that the diesel fuel showed lower exhaust gas temperature compared to all the biodiesel blends at all loads owing to higher oxygen mixture in the biodiesel blends. Ozsezen and Canakci [6] investigated the performance of a CI engine fuelled with canola and palm oil bio fuels. The results indicated that the brake power reduced by $5 \%$ and the BSFC increased by $10 \%$. Conversely, CO reduced by $67 \%$, $\mathrm{HC}$ by $26 \%, \mathrm{CO}_{2}$ by $8 \%$, and smoke opacity by $63 \%$. But $\mathrm{NO}_{x}$ emissions increased by $22 \%$ compared with diesel. Laurencas Raslavičius and Žilvinas Bazaras [7] analyzed the motor characteristics of diesel-rapeseed methyl esterethanol fuel blend during on-field tests. They reported that the presence of oxygen content in blends positively influenced the combustion process and reduced the solid particles, hydrocarbon and $\mathrm{CO}$ emission in exhaust gas. Song et al [8] investigated the influence of oxygenated fuel on combustion and emission characteristics of a CI engine. A blend of monoglyme and diglyme was used as a diesel reformulating agent. The results inferred that the oxygenated fuel reduced particulate matter with a small increment of $\mathrm{NO}_{\mathrm{x}}$ at high load. Reduction in $\mathrm{HC}$ and $\mathrm{CO}$ emission was observed. Liaquat et al [9] studied the influence of coconut biodiesel on engine performance and emission characteristics of a CI engine. It is reported that torque and brake power decreased while SFC increased for biodiesel compared to standard diesel. Reduction in $\mathrm{HC}$ and $\mathrm{CO}$ emission was observed while higher $\mathrm{CO}_{2}$ and NOx emissions were observed for biodiesel compared to diesel fuel. Investigation was carried out on a CI engine at different loads and at different injection timings to study the characteristics of direct injection (DI) diesel engine fuelled with ethyl ester of fish oil and its blends [10]. Azeem et al [11] studied extraction of bio fuel from low cost, renewable and plentiful date seed oil. It is reported that bio fuel extracted from date seed oil has high cetane number, low iodine value and good flash point. Laurencas Raslavicius et al. [12] investigated the performance and emission characteristics of CI engine fuelled with P. moriformis oil and its blends with diesel fuel. They assessed the parameters such as variation of in-cylinder pressure, in-cylinder pressure rise rate, in-cylinder temperature, mass fraction burnt, in-cylinder temperature rise rate and in-cylinder heat release rate with respect to thermochemical processes during combustion. They reported that the higher calculated cetane index of unary and binary blends of P. moriformis oil shortens the premixing time and moves the combustion phasing earlier in the compression stroke. Shanmughasundaram et al. [13] studied the effect of inlet air pre heater on CI engine performance and emission using corn oil biodiesel blends. The BTE increased by $25 \%$ when the air temperature was increased from $35^{\circ} \mathrm{C}$ to $50^{\circ} \mathrm{C}$. Dinesh and Metin Kok [14] reviewed different parameters affecting the vehicle emission gases of different fuel mode operations.

Laurencas Raslavičius and Žilvinas Bazaras [15] studied the possibility of increasing the quantity of oxygenates in rapeseed methyl ester (RME) and dehydrated ethanol fuel blends. It is reported that the concentration of unburnt $\mathrm{HC}$ emitted from the over-lean regions depends on the amount of fuel injected during the ignition delay period that is shorter for RME due its higher cetane number. The positive and negative aspects of applying bio-based addi- 
tives in diesel are reported and discussed. Roy et al. [16] studied the effective utilization of waste cooking oil in a CI engine using alumina nano particles. Gurz et al. [17] reviewed the usage of hydrogen in automobile vehicles. It is reported that hydrogen is lighter than air, flammable and explosive but less threat than gasoline. It has minimum ignition energy and highly sensitive to fire. Miyamoto et al [18] investigated addition of hydrogen on performance and emission characteristics of a CI engine.

Hydrogen alone cannot be employed in CI engines as it requires a very high compression ratio due to its high auto ignition temperature, $858 \mathrm{~K}$. Moreover, addition of hydrogen with diesel affects the air-fuel ratio of the diesel engine as hydrogen uses up some of the oxygen in the air. It resulted in poor diesel combustion and thermal efficiency. As a solution to the low oxygen problem, oxyhydrogen (HHO) can be introduced. The blending of $\mathrm{HHO}$ leads to the increased oxygen concentration, which is capable of enhancing the combustion for the fuel-air mixtures and improves the engine thermal efficiency [19].

Yilmaz et al. [20] studied the influence of HHO gas on performance and emission characteristics of a CI engine. They reported that engine torque increased by $19 \%$.CO, HC and SFC reduced by $13 \%, 5 \%$ and $14 \%$ respectively. Combustion efficiency of the engine operated with diesel fuel is improved under high speed conditions owing to the high flame speed, shorter quenching distance and wide flammability range of hydroxy gas. Kundu et al [21] studied the production of hydrogen gas from water employing electrolytic process at room temperature. It is reported that on-board hydrogen production is an alternative route because unavailability of quality hydrogen storage system. They studied the rate of hydrogen production with respect to the factors such as concentrations of the electrolytic solution, electrodes gap, and number of electrodes. Koten [22] studied the impact of hydrogen on the $\mathrm{CI}$ engine performance and emissions.

Liu et al. [23] reported that HHO accelerates the oxidation process and $\mathrm{CO}, \mathrm{HC}$ and smoke emission declined gradually when load increased, but the drop of NO was comparatively smaller. Addition of $20 \%$ hydrogen leads poor diesel-air quantity which is not sufficient to develop healthy flame to ignite the hydrogen-diesel-air mixture. It reduces peak cylinder pressure and the combustion efficiency drastically. Oxy-hydrogen gas (HHO) generator can be used effectively to generate $\mathrm{HHO}$ gas up to a certain limit to overcome the difficulties in storing the hydrogen [24-25].

Cooking oils are used for cooking, frying, and food preservation. Once oils are used, they are simply wasted. It is possible to recycle and transform them into bio fuel. It is reported that 10 Million litres of diesel fuel is consumed every month in India according to the annual data 2019. The government of India is planning to blend $5 \%$ of bio fuel in diesel by 2030 . Therefore 5 billion litres of bio fuels are required per year. It is estimated that 27 billion litres of cooking oil are used in India and 1.4 billion used cooking oil can be collected from bulk consumers such as hotels, restaurants and canteens for conversion, which would give around 1.10 billion litres of bio fuel every year. Few authors have studied the performance and emission of the engine fuelled with waste cooking oil [26$28]$. From the outcomes of literatures, it was observed that a very limited research has been reported on using $\mathrm{HHO}$ as a secondary fuel in a $\mathrm{CI}$ engine. Moreover, blends of $\mathrm{HHO}$ gas and UCO bio diesel has not been drawn much attention among the researchers. The novelty of this work is to study the combustion, performance and emission characteristics of the CI engine operated with blends of $\mathrm{HHO}$ gas and bio diesel which is extracted from the used cooking oil (UCO) i.e., from the mixture of castor oil, coconut oil, palm oil, rice bran oil, canola oil, corn oil, soybean oil, sun flower oil, peanut oil, sesame oil and flax seed oil.

\section{Materials and methodology}

\subsection{Materials}

In this study, fuels used are standard diesel, Used Cooking Oil (UCO) biodiesel and Hydroxyl (HHO) gas. For all load conditions, standard diesel (100\% Standard diesel), B20 blend (20\% UCO Bio fuel+ $80 \%$ standard diesel) and B20+HHO blend (20\% UCO Bio fuel+ $80 \%$ standard diesel+ HHO) were selected for this study. 0.50 $\mathrm{lpm}$ flow rate of HHO was chosen. Properties of diesel, $\mathrm{UCO}$ bio fuel and $\mathrm{H}_{2}$ gas are given in Table 1.

Table 1

Properties of diesel, UCO bio fuel and $\mathrm{H}_{2}$ gas

\begin{tabular}{|c|c|c|c|c|}
\hline Properties & $\begin{array}{c}\text { Test meth- } \\
\text { od, ASTM }\end{array}$ & Diesel & $\begin{array}{c}\text { UCO } \\
\text { Bio fuel }\end{array}$ & $\mathrm{H}_{2}$ \\
\hline Density, kg/m & D 4052 & 831 & 925 & 0.08 \\
\hline LHV, MJ $/ \mathrm{kg}$ & D 4809 & 43.6 & 35.5 & 119.93 \\
\hline Cetane number & D 613 & 51 & 56 & - \\
\hline Octane number & B2699 & - & - & 130 \\
\hline $\begin{array}{c}\text { Auto Ignition tem- } \\
\text { perature }{ }^{\circ} \mathrm{C}\end{array}$ & E659 & 257 & 320 & 585 \\
\hline
\end{tabular}

Used cooking oil (UCO) was collected from individuals, restaurants, hostels and food industries. Biofuel was extracted employing transesterification process.

A variable compression ratio multi fuel engine (Fig. 1) was employed and engine specifications are given in Table 2.

Accomplishing order for engine stand tests:

1. Engine was started and run at a rated speed of $1500 \mathrm{rpm}$ under no-load condition until engine oil temperature reached the threshold value of $90^{\circ} \mathrm{C}$.

2. The engine was operated at a constant speed of 1500 rpm by varying the four different percentages of loads $(25 \%, 50 \%, 75 \%$, and $100 \%)$ i.e., $0.93 \mathrm{~kW}, 1.85 \mathrm{~kW}$, $2.78 \mathrm{~kW}$ and $3.7 \mathrm{~kW}$ to measure the performance and emission variables. Engine load was varied employing the eddy current dynamometer.

3 . Fuel injection pressure and injection timing were maintained at 200 bar and $23^{\circ} \mathrm{CA}$ bTDC respectively.

4. Engine test runs were performed in fair constant ambient conditions $\left(27^{\circ} \mathrm{C}, 55 \% \mathrm{RH}\right)$. After finishing each test, the engine was run for approximately 10 minutes to burn out the residues of previous tested fuel.

5. All the accessories of gas analyzerand smoke meter were checked as per guide lines of manufacturer. Zero and span calibration was carried out using sample exhaust gas. 6. Each test was repeated three times and the mean value of three measurements was considered for calculation to minimize errors and reduce the uncertainties in measurement. 
7. Fuel filter media was changed when the engine was tested with the higher blending ratio of bio diesel in order to avoid filter plugging problems.

Air flow rate $\left(\mathrm{m}^{3} / \mathrm{hr}\right)$ was measured by differential pressure transducer with digital indicator. Fuel consumption $(\mathrm{kg} / \mathrm{hr})$ was measured by load cell based, loss in weight type with indicator. Water flow rate $(\mathrm{cc} / \mathrm{s})$ was measured by turbine type flow sensor with indicator for engine and calorimeter. Piezo Electric pressure sensor with cooling adopter was provided to measure combustion pressure inside the engine cylinder. This test rig is provided with necessary lab view based software for performance analysis. With respect to engine performance, Brake specific fuel consumption (BSFC) and Brake thermal efficiency (BTE) parameters were analyzed. The emissions namely carbon monoxide, hydrocarbon, NOx and smoke were recorded.

Hydroxyl (HHO) gas generator (electrolyser) which was employed for this study is shown in Fig. 2. It was fabricated under the principle of electrolysis method. Hydrogen gas is generated by decomposition of water by passing an electric current between the electrodes. A $12 \mathrm{~V}$ $65 \mathrm{Ah}$ battery was employed as a power supply. HHO generator is composed of stainless-steel plates which has good electrical, thermal and physical properties. Non-return valve is provided between the electrolyser and bubbler to prevent backfire. Intake air pipe was modified to have inlet port for admitting $\mathrm{HHO}$ gas in to the cylinder.

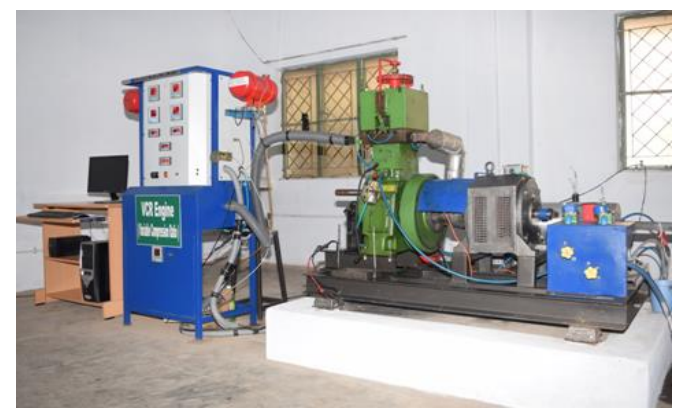

Fig. 1 Variable compression ratio compression ignition engine

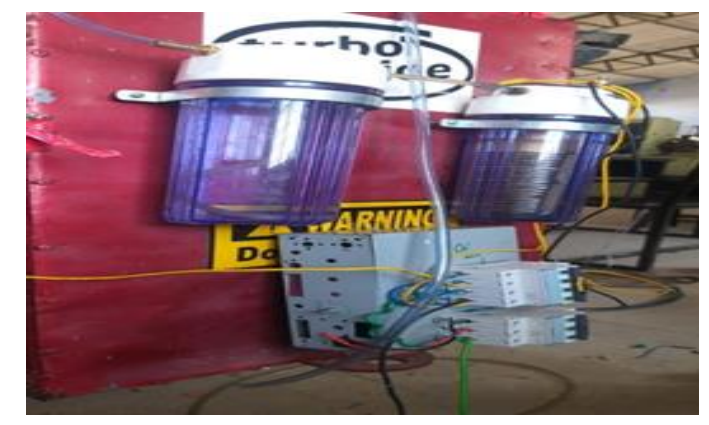

Fig. 2 HHO gas generator

Specifications of the engine

Table 2

\begin{tabular}{|l|l|}
\hline Make & $\begin{array}{l}\text { Kirloskar, Variable Compression } \\
\text { ratio Multi Fuel engine }\end{array}$ \\
\hline Type & Single cylinder, 4 stroke, CI \\
\hline Injection & Direct \\
\hline Power, $\mathrm{kW}$ & 3.7 \\
\hline Engine speed, rpm & 1500 \\
\hline Cooling Medium & Water \\
\hline Cylinder Volume, $\mathrm{cm}^{3}$ & $551($ stroke $11 \mathrm{~cm}$, bore $8 \mathrm{~cm})$ \\
\hline Compression ratio & $5: 1$ to $20: 1($ variable) \\
\hline
\end{tabular}

The engine was operated and CO, HC, NOx and smoke were recorded for each test after 10 minutes. The specification of gas analyzer (AVL DIGAS 444) and smoke meter (AVL 437C) is given in Table 3.

Table 3

Specifications of AVL DIGAS 444 exhaust gas analyzer and smoke meter

\begin{tabular}{|c|c|c|}
\hline Gas & Measurement range & Resolution \\
\hline $\mathrm{CO}$ & $0-10 \%$ Vol. & $0.01 \%$ Vol. \\
\hline $\mathrm{HC}$ & $0-20000 \mathrm{ppm}$ Vol. & $\begin{array}{c}1 \mathrm{ppm} / 10 \mathrm{ppm} \\
(0-2000 \mathrm{ppm}) /(>2000 \mathrm{ppm})\end{array}$ \\
\hline $\mathrm{CO}_{2}$ & $0-20 \%$ Vol. & $0.1 \%$ Vol. \\
\hline $\mathrm{O}_{2}$ & $0-22 \%$ Vol. & $0.01 \%$ Vol. \\
\hline $\mathrm{NO}$ & $0-5000 \mathrm{ppm}$ Vol. & $1 \mathrm{ppm} / \mathrm{Vol}$. \\
\hline Smoke & $0-100 \%$ & $0.1 \%$ \\
\hline
\end{tabular}

\subsection{Uncertainty analysis}

The experimental accuracy was computed by uncertainty analysis wherein the measuring device errors and ecological conditions were taken into consideration. Percentage uncertainties were computed using the uncertainty of the respective parameters. The maximum percentage uncertainties of the parameters such as brake specific fuel consumption (BSFC), brake thermal efficiency (BTE), carbon monoxide, HC emission, NOx emission and smoke opacity were $2.05 \%, 2.13 \%, 2.27 \%, 2.19 \%, 1.25 \%$, and $1.2 \%$ respectively. The overall uncertainty of the experiment was computed by considering uncertainty of individual parameters using the principle of root-mean-square given by Holman (29).

Total percentage of the uncertainty $=[(\mathrm{BSFC}) 2+$ $+(\mathrm{BTE}) 2+(\mathrm{CO}) 2+(\mathrm{HC}) 2+(\mathrm{NOx}) 2+$ $+($ Smoke $) 2] 1 / 2$

The uncertainty analysis of various instruments is shown in Table 3. The overall experimental error was calculated by the Eq. which was found to be $\pm 4.657 \%$.

\section{Results and discussion}

\subsection{Combustions characteristics of the engine}

\subsubsection{Peak in-cylinder pressure}

Variation of cylinder pressure with respect to crank angle at a load of $3.7 \mathrm{~kW}$ for standard diesel, B20 blends and B20+HHO blends are shown in Fig. 3, Fig. 6 and Fig. 9 respectively. The corresponding pressure - volume diagrams are portrayed in Fig. 4, Fig. 7 and Fig. 10. The maximum peak pressure was recorded when the engine was run at full load as more fuel is being burnt at higher loads. It can be seen that the peak cylinder pressure of the engine fuelled with diesel, B20 blend, B20+HHO blends are 60 bar, 58 bar and 63.5 bar respectively. The peak cylinder pressure for diesel-fuelled engine is 60 bar, occurring at $367^{\circ}$ crank angle. It can be seen from the Fig. 6 that the peak cylinder pressure is observed to be 58 bar which occurs at $364^{\circ}$ crank angle when the engine was operated blend with B20 blends. It infers that the peak pressure occurs earlier ( $3^{\circ}$ in advance) compared with standard diesel owing to higher cetane value of bio fuel. 
However, peak cylinder pressure is slightly reduced when the engine was operated with B20 blends due to lower heating value and energy density of bio fuel. Addition of HHO gas with B20 increased the cylinder pressure from 58 bar to 63.5 bar which occurs at $362^{\circ}$ crank angle compared to B20.It can be attributed due to decrease in ignition delay (30) and high flame temperature and flame speed of hydrogen (31). The peak pressure occurred in $5^{\circ}$ advance for hydrogen induction compared with diesel and $2^{\circ}$ advance compared with B20.Total duration of combustion is shorter for B20+HHO blends compared to B20 biodiesel.

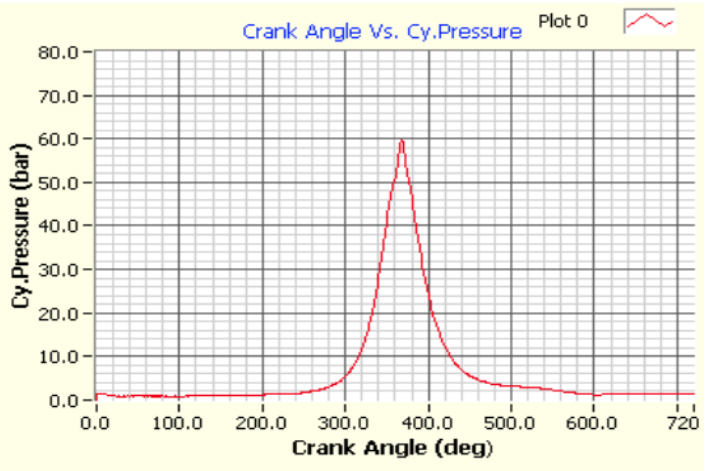

Fig. 3 Pressure crank-angle diagram for standard diesel

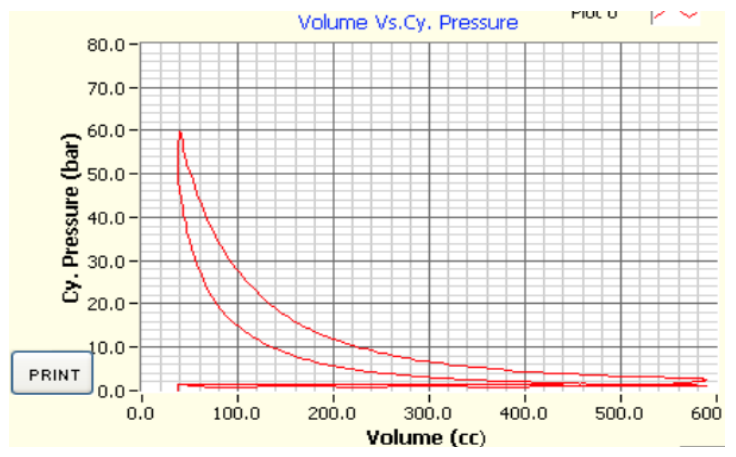

Fig. 4 Pressure -Volume diagram for standard diesel

\subsubsection{Net heat release rate}

Variation of heat release rate with respect to crank angle at a load of $3.7 \mathrm{~kW}$ for standard diesel, B20 blends and $\mathrm{B} 20+\mathrm{HHO}$ blends are shown in Figs. 5, 8 and 11 respectively. Combustion behaviour of fuels, phases of combustion and combustion duration can be known from the heat release rate. The heat release rate is defined as chemical energy of fuel released during the combustion process and it is primarily dependent on the quality of fuel, A/F ratio, mixing of air and fuel, load, compression ratio and injection parameters. It was observed that tested fuels demonstrated the same trend of heat release for all type of loads. The peak heat release rate for standard diesel, B20 blend and B20+HHO blends are 13J/Deg.CA, 10.5J/Deg.CA, and 15J/Deg.CA respectively. B20+HHO blends have higher HRR and it is due to the addition of HHO compared to diesel and B20 blends. The peak HRR decreased for biodiesel-fuelled engine by $19 \%$ compared with engine fuelled with diesel due to lower calorific value of B20 blends. On other hand the HRR increased for B20+HHO blends fuelled engine by $15 \%$ compared with engine fuelled with diesel. Higher flame propagation speed and instantaneous combustion behaviour of $\mathrm{HHO}$ gas increases the HRR significantly. Addition of HHO resulted in higher peak pressure and higher heat release ratedue to shorter ignition delays (30).

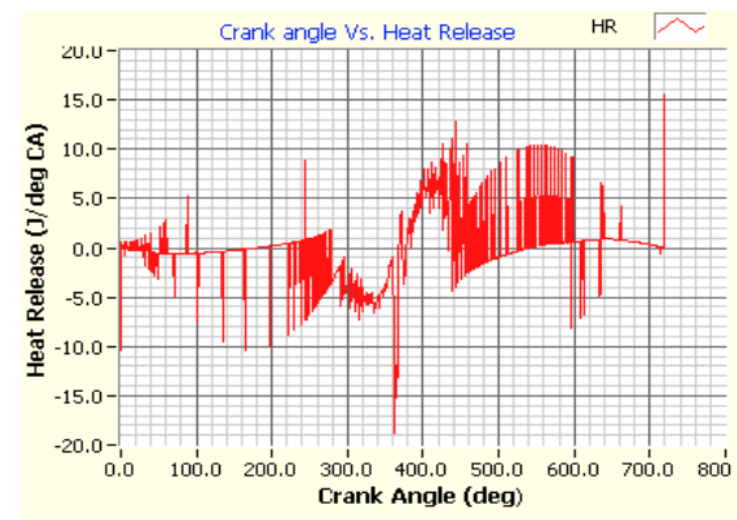

Fig. 5 Heat release rate - crank-angle diagram for standard diesel

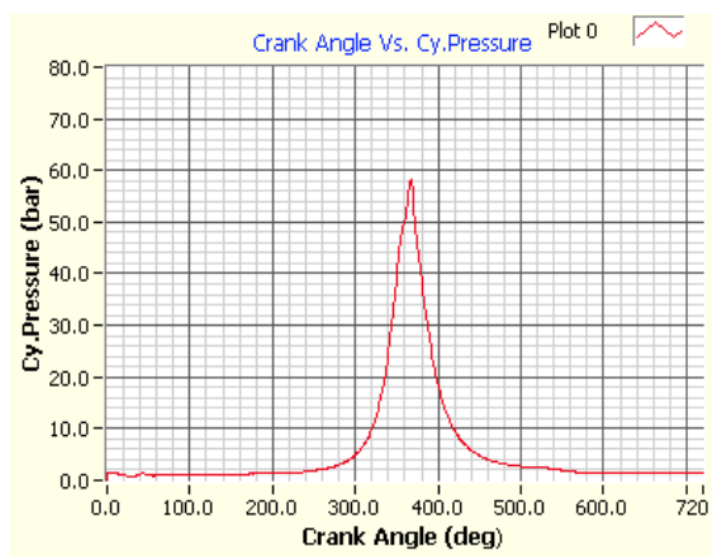

Fig. 6 Pressure crank-angle diagram for B20 blend

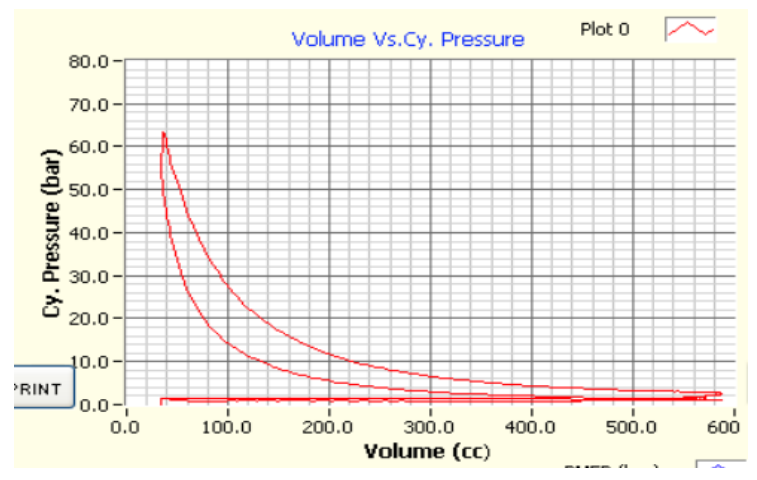

Fig. 7 Pressure - Volumediagram for B20 blend

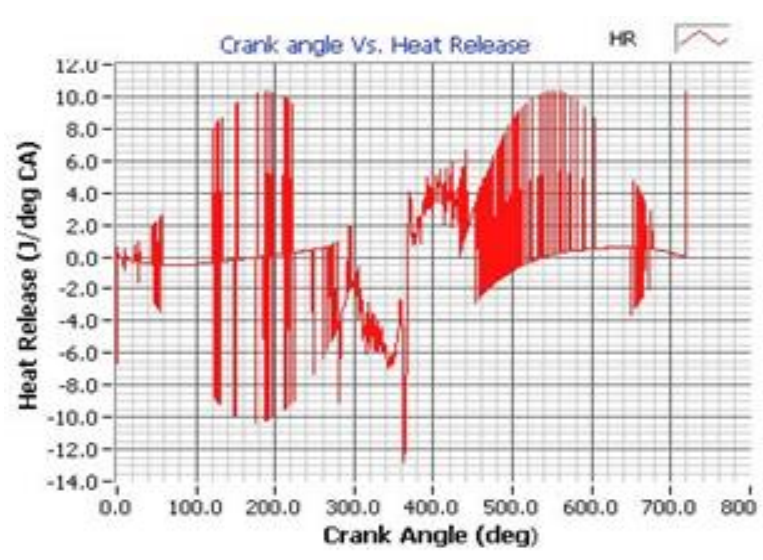

Fig. 8 Heat release rate - crank-angle diagram for B20 blend 


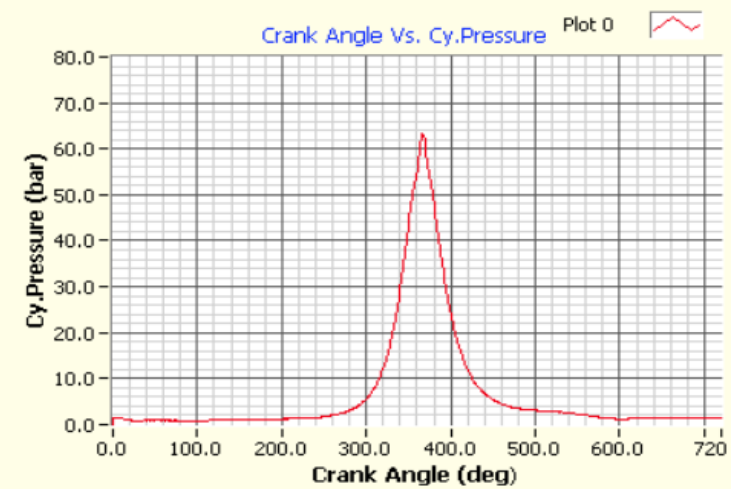

Fig. 9 Pressure crank-angle diagram for B20 +HHO blend

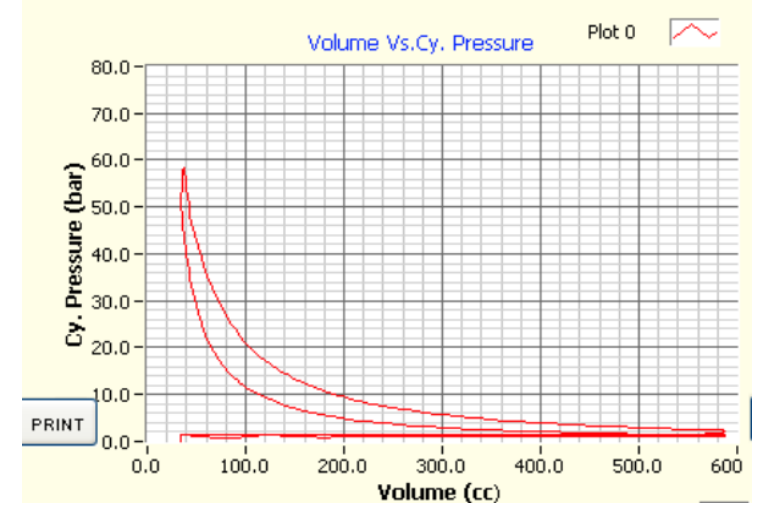

Fig. 10 Pressure - Volume diagram for B20 + HHO

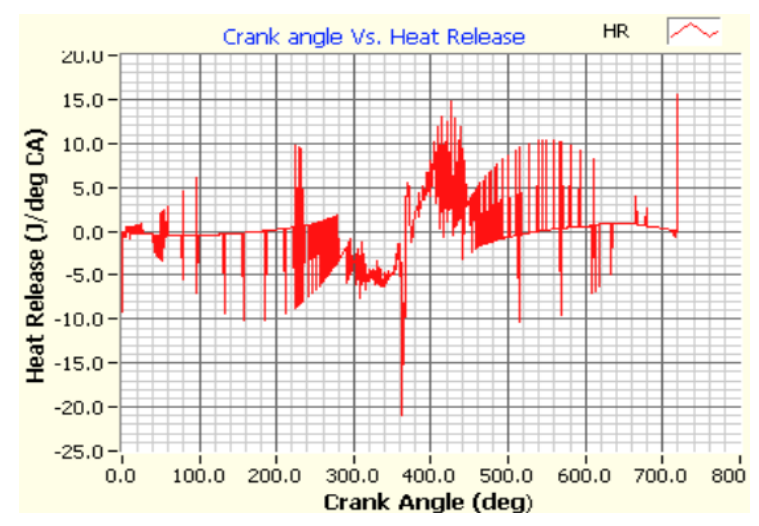

Fig. 11 Heat release rate - crank-angle diagram for B20 + HHO blend

\subsection{Performance characteristics of the Engine}

\subsubsection{Brake Specific Fuel Consumption (BSFC)}

Fig. 12 shows the variation of BSFC with respect to brake power for the three different fuels such as standard diesel, B20 blend and $\mathrm{B} 20+\mathrm{HHO}$ blends. BSFC tends to decrease with increasing load irrespective of fuels tested and it attained a minimum value at full load. BSFC of the engine decreased when the engine was operated with B20+HHO blends compared to diesel and B20 blends. At $3.7 \mathrm{~kW}$ engine load, the BSFC was $0.41 \mathrm{~kg} / \mathrm{kWh}$ for B20+HHO blend. On the other hand, BSFC was observed to be $0.44 \mathrm{~kg} / \mathrm{kWh}$ and $0.46 \mathrm{~kg} / \mathrm{kWh}$ for diesel and B20 blends respectively.

In case of B20 blend, engine consumes relatively more fuel than diesel at the same power due to its lower heating value and longer injection duration due to the higher density of the bio fuel. Minimum BSFC was achieved when the engine operated with B20+HHO blends. It can be noted that BSFC of the engine operated with $\mathrm{B} 20+\mathrm{HHO}$ blends decreased by $7.31 \%$ compared to diesel and $12.19 \%$ compared to B20 blend. HHO enhances the complete combustion as it has high flame speed and octane rating. Addition of $\mathrm{HHO}$ gas enhances the combustion efficiency particularly at high speed conditions where the bio fuel blends is hard to combust completely as a result of higher residual gas and poor mixing at lean conditions [31].

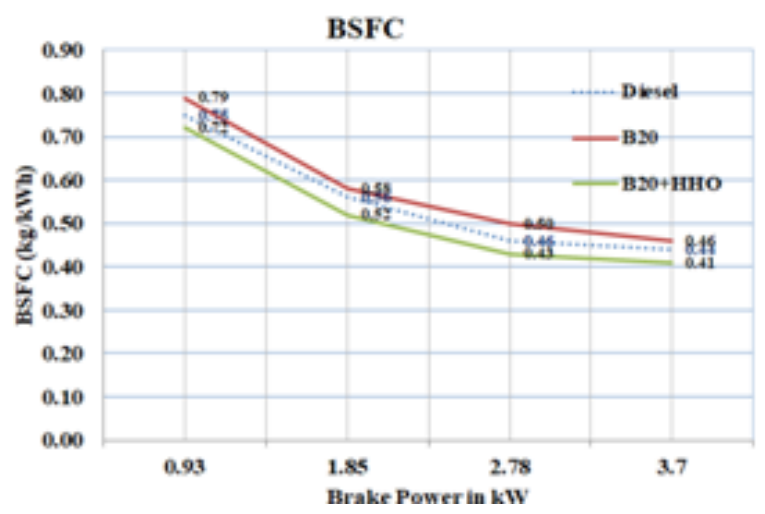

Fig. 12 Variation of BSFC with respect to brake power and fuels

\subsubsection{Brake thermal efficiency}

Fig.13 depicts the variation of brake thermal efficiency with respect to brake power for the three different fuels such as standard diesel, B20 blend and B20+HHO blends. It can be seen that the BTE increases with increasing the load irrespective of the fuels tested. BTE is slightly lower for B20 blends compared to diesel fuel at all engine loads.

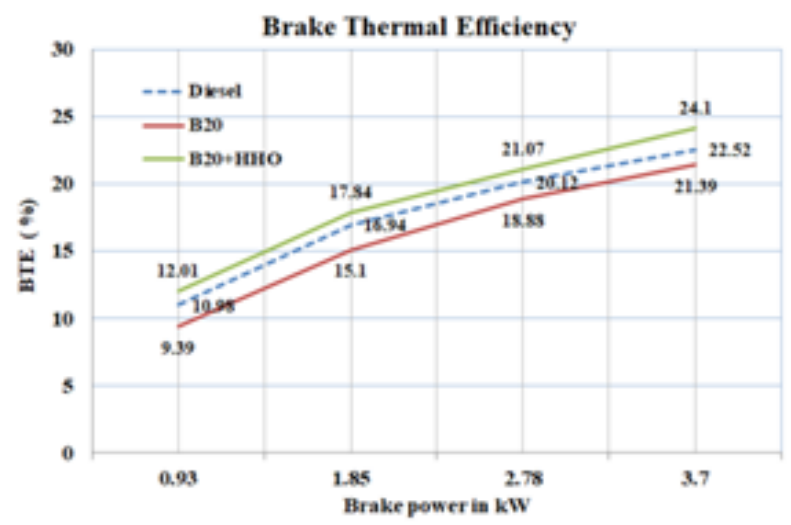

Fig. 13 Variation of brake thermal efficiency with respect to brake power and fuels

BTE of the engine operated with B20 bio diesel blend is adversely affected due to the lower heating value of bio fuel blend. BTE of the engine is increased significantly when the engine was operated with B20+HHO blends compared with diesel and B20 blend. The BTE of the engine at a load of $3.7 \mathrm{~kW}$ was recorded to be $22.52 \%$ for diesel, $21.39 \%$ for B20 and $24.1 \%$ for B20+HHO. The highest BTE was found to be $24.1 \%$ for B20+HHO blends. It can be noted that BTE of the engine operated with B20+HHO blends increased by $7 \%$ compared to diesel and $12.66 \%$ compared to B20 blend. Addition of HHO gas 
enhances the octane rating of any low-grade fuel. Moreover, hydrogen has a flammability range of $4 \%-75 \%$ by volume in air which is very high compared to diesel's $0.7 \%-5 \%$ by volume. Moreover, it has a high diffusion coefficient, $0.61 \mathrm{~cm}^{2} / \mathrm{swhich}$ enhances homogeneous airfuel mixture inside the combustion chamber (32).

The increase in BTE of the engine operated with B20+HHO is owing to the uniformity in mixture formation and higher flame speed of hydrogen which assists to have more complete combustion resulting in an improvement in BTE at all load conditions. Wider flammability limit and higher burning speed of hydrogen enhances combustion and gains a higher brake thermal efficiency (33).

\subsection{Emission characteristics of the engine}

\subsubsection{CO emission}

Fig.14 depicts the variation of $\mathrm{CO}$ emission with respect to brake power for the three different fuels such as standard diesel, B20 blend and B20+HHO blends. CO emission tends to increase by varying load till $75 \%$ of engine load i.e., $2.78 \mathrm{~kW}$. As load increases, the cylinder temperature increases and enhances the combustion.

Conversely $\mathrm{CO}$ is slightly increased at higher load. It is due to the lack of oxygen at higher load as rich $\mathrm{A} / \mathrm{F}$ mixture is burnt. B20 blends showed considerable reduction in $\mathrm{CO}$ emission compared with diesel as $\mathrm{UCO}$ bio diesel has more oxygen molecules which promotes the complete combustion.

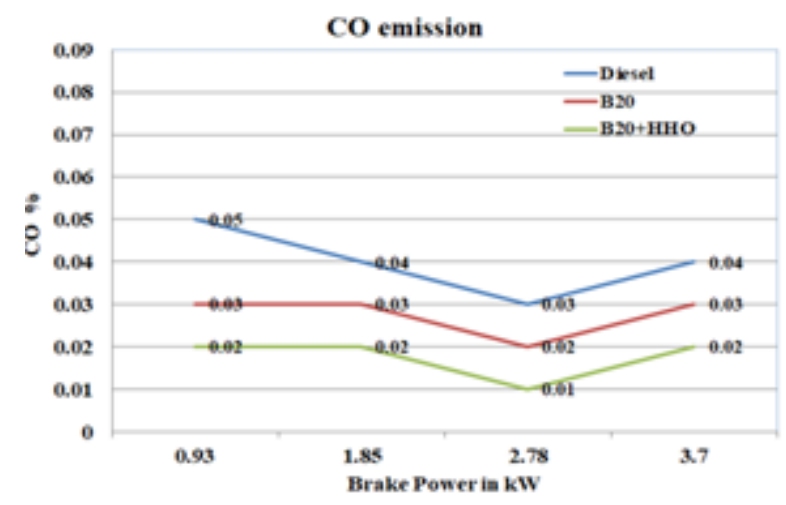

Fig. 14 Variation of $\mathrm{CO}$ emission with respect to brake power and fuels

This is supported by Chauhan et al. [34] who reported that a higher cetane number and oxygen content of biodiesel exhibits a shorter ignition delay period and enhances combustion. Fig.14 also illustrates the influence of $\mathrm{HHO}$ on $\mathrm{CO}$ emission under different loads. It can be noted that $\mathrm{CO}$ tends to decrease with addition of HHO. The $\mathrm{B} 20+\mathrm{HHO}$ blends burns faster and more completely than the standard diesel and B20 blends as HHO gas contains oxygen and enhanced combustion characteristics of $\mathrm{HHO}$ gas. CO levels were lesser with injection of HHO due to presence of higher amount of oxygen in the combustion chamber along with the lean mixture (30).

\subsubsection{HC emission}

Fig. 15 depicts the variation of $\mathrm{HC}$ emission with respect to brake power for the three different fuels such as standard diesel, B20 blend and B20+HHO blends. HC emission occurs primarily due to the incomplete combustion which depends on the properties of the fuels used and engine operating parameters. A decreasing trend of $\mathrm{HC}$ emission was observed upon increasing the load till $75 \%$ of engine load i.e., $2.78 \mathrm{~kW}$. As load increases, the cylinder temperature tends to increase and enhances better combustion and reduces $\mathrm{HC}$ emission. On the other hand, HC tends to increase slightly at higher load due to the lack of oxygen as rich $\mathrm{A} / \mathrm{F}$ mixture is combusted. $\mathrm{HC}$ emission was found to be $25 \mathrm{ppm}$ for B20 blend and $28 \mathrm{ppm}$ for diesel at full load of $3.7 \mathrm{~kW}$. HC emission is decreased by $10.71 \%$ for biodiesel compared to diesel. Bio diesel exhibits lower HC emission than diesel because of presence of oxygen molecules in the bio fuel. The engine operated with $\mathrm{B} 20+\mathrm{HHO}$ blend yields lower $\mathrm{HC}$ emission compared to diesel and B20 blends. The $\mathrm{HC}$ emission was found to be $18 \mathrm{ppm}$ at $3.7 \mathrm{~kW}$ load for B20+HHO blend. HC emission is decreased by $35 \%$ for $\mathrm{B} 20+\mathrm{HHO}$ blend compared to diesel. This can be possibly explained that thehigher diffusivity and wider flammability of $\mathrm{H}_{2}$ gas and presence of $\mathrm{O}_{2}$ molecules enhances the combustion efficiency and declines HC formation drastically (30).

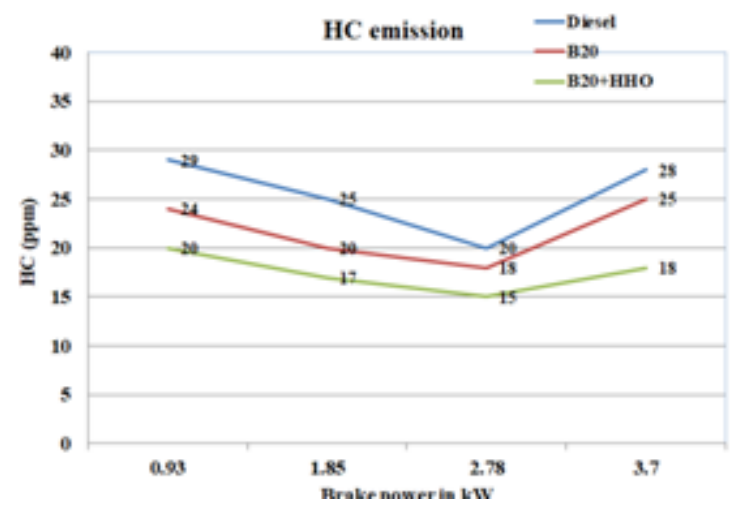

Fig. 15 Variation of $\mathrm{HC}$ emission with respect to brake power and fuels

During combustion, HHO generated more $\mathrm{OH}$ free radicals which enhance the reaction with the $\mathrm{C}-\mathrm{H}$ chain due to its strong oxidizing properties and continuously oxidized unburned $\mathrm{HC}$ after the main combustion period. Thus, HC emission is reduced (35). Higher diffusion speed of hydrogen makes the fuel mixture gain better homogeneity, and therefore enhances the engine thermal efficiency and reduces the unburnt HC emissions (31).

\subsubsection{Nox emission}

The main components of $\mathrm{NOx}$ are $\mathrm{NO}, \mathrm{NO}_{2}$, which are dangerous to the human and environment such as acid rains, smog and ground-level ozone formation. It can be seen from the Fig. 16 that NOx emissions increased with the increasing engine load on account of increasing combustion temperature. Higher in-cylinder pressure and temperature lead the formation of more valance oxygen and nitrogen atoms by dissociation of air, which finally produces more NOx at tailpipe. NOx emission was found to be $19 \mathrm{ppm}$ for B20 blend and $16 \mathrm{ppm}$ for diesel at full load of $3.7 \mathrm{~kW}$. NOx emission is increased by $18 \%$ for biodiesel compared to diesel. Bio diesel exhibits higher NOx emission than diesel because of presence of oxygen molecules in the bio fuel which enhances the combustion 
and increases the combustion temperature. On the other hand, addition of bio fuel quantity exceeds B20 caused poor thermal efficiency due to the lower calorific value and higher viscosity of bio diesel. The NOx emission was found to be $21 \mathrm{ppm}$ at $3.7 \mathrm{~kW}$ load for B20+HHO blend. It was observed from our earlier work, NOx tended to increase considerably when the addition of HHO into the inlet air exceeds $0.50 \mathrm{lpm}$. Various researchers have found a similar result of increased NO emissions with $\mathrm{HHO}$ addition (36). NOx emission was also reported higher only when diesel and biodiesel blends enriched with HHO (38). Higher diffusivity and wider flammability of $\mathrm{H}_{2}$ gas enhances the combustion efficiency which increases NOx formation. It can also be observed that HHO addition with B20 blend increases the peak cylinder pressure and temperature which results in higher NOx emission.

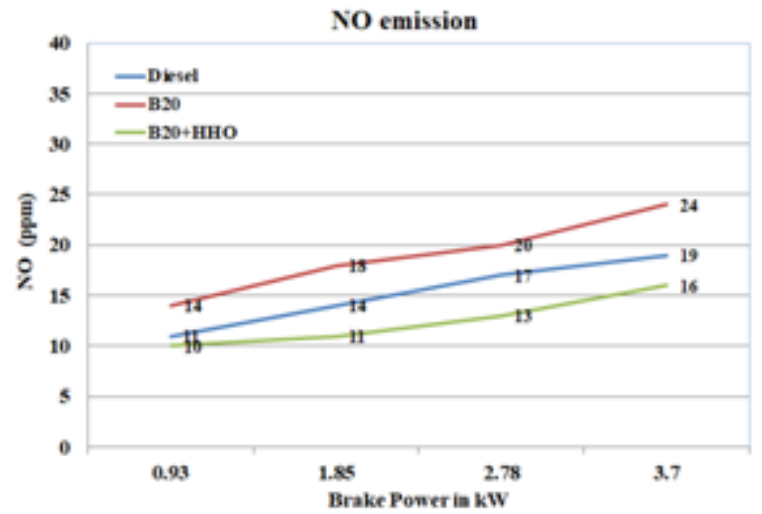

Fig. 16 Variation of NOX emission with respect to brake power and fuels

\subsubsection{Smoke emission}

Fig. 17 represents the effect of smoke emission against different engine load conditions for diesel, B20, and B20+HHOfuels. The particulates are formed due to incomplete combustion of hydro carbons. The smoke opacity for fuel blendB20+ HHO, B20 and diesel was observed to be $23 \%, 25 \%$, and $33 \%$, respectively, at $3.7 \mathrm{~kW}$ load conditions.

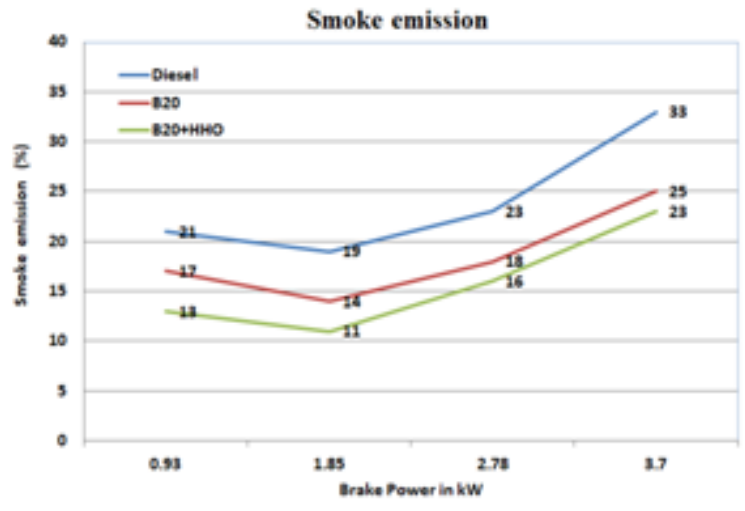

Fig. 17 Variation of smoke emission with respect to brake power and fuels

Results inferred that smoke emission was found to be maximum at higher load. It was also observed that smoke emission for B20 blend is less compared to diesel. This is attributed to the presence of higher oxygen content in the biodiesel (32) and the higher the cetane number which lowers the probability of fuel- rich zones formation. Moreover, with HHO additions, the smoke was found to be lower compared to $\mathrm{B} 20$ blends. $\mathrm{H}_{2}$ and $\mathrm{O}_{2}$ additives reduce concentrations of incomplete combustion products $\mathrm{CO}$ and $\mathrm{HC}$ as well as the smokiness of the exhaust drastically (3738). This can be ascribed to the fact that the addition of the hydroxyl increases the oxygen concentration which benefits enhancing the complete combustion of the fuel and thus lower formation of emission.

\section{Conclusions}

The present study investigated the influence of used cooking oil bio diesel blend and HHO gas on combustion, performance and emission characteristics of a variable compression ratio $\mathrm{CI}$ engine. Following results are drawn from the tests conducted. Engine operated with B20+HHO blends have higher HRR compared to diesel and B20 blends. HRR increased for B20+HHO blends fuelled engine by $15 \%$ compared with engine fuelled with diesel. BSFC of the engine operated with B20+HHO blends decreased by $7.31 \%$ compared to diesel and $12.19 \%$ compared to B20 blend. HHO enhances the complete combustion as it has high flame speed and octane rating. The highest BTE was found to be $24.1 \%$ for $\mathrm{B} 20+\mathrm{HHO}$ blends. BTE of the engine operated with B20+HHO blends increased by $7 \%$ compared to diesel and $12.66 \%$ compared to B20 blend. $\mathrm{CO}$ tends to decrease with addition of $\mathrm{HHO}$. The engine operated with $\mathrm{B} 20+\mathrm{HHO}$ blend yields lower $\mathrm{HC}$ emission compared to diesel and B20 blends. The HC emission was found to be $18 \mathrm{ppm}$ at $3.7 \mathrm{~kW}$ load for $\mathrm{B} 20+\mathrm{HHO}$ blend. HC emission is decreased by $35 \%$ for B20+HHO blend compared to diesel. The NOx emission was found to be $21 \mathrm{ppm}$ at $3.7 \mathrm{~kW}$ load for $\mathrm{B} 20+\mathrm{HHO}$ blend. NOx tended to increase considerably when the addition of HHO into the inlet exceeds $0.501 \mathrm{pm}$. Moreover, with HHO additions, the smoke was found to be lower compared to B20 blends.

Results inferred that HHO can be used as a supplementary fuel in addition with used cooking oil bio diesel without modifying the existing CI engine. Use of $\mathrm{HHO}$ gas in fuel enrichment has several benefits apart from knocking and reduction in volumetric efficiency. Hence further research can be focussed on the use of $\mathrm{HHO}$ as additive fuel inlow-temperature combustion (LTC) with homogeneous charge compression ignition (HCCI) engine which can be employed to attain low emissions of NOx and soot.

\section{References}

1. Chen, R. X.; Wang, W. C. 2018. The production of renewable aviation fuel from waste cooking oil. Part I: Bio-alkane conversion through hydro-processing of oil. Renewable Energy. https://doi.org/10.1016/j.renene.2018.12.048.

2. Senthur Prabu, S.; Asokan, M. A.; Roy, R.; Francis, S.; Sreelekh, M. K. 2017. Performance, combustion and emission characteristics of diesel engine fuelled with waste cooking oil bio-diesel/diesel blends with additives, Energy 122: 638-648. https://doi.org/10.1016/j.energy.2017.01.119.

3. Ali, M. A. Attia; Ahmad, E.; Hassaneen. 2016. Influence of diesel fuel blended with biodiesel produced 
from waste cooking oil on diesel engine performance, Fuel 167: 316-328.

4. Rizwanul Fattah, I. M.; Masjuki, H. H.; Kalam, M. A.; Mofijur, M.; Abedin, M. J. 2014. Effect of antioxidant on the performance and emission characteristics of a diesel engine fueled with palm biodiesel blends, Energy Conversion and Management 79: 265-272.

5. Chaurasiya, P. K.; Singh, S. K.; Dwivedi, R.; Choudri, R. V. 2019. Combustion and emission characteristics of diesel fuel blended with raw jatropha, soybean and waste cooking oils, Heliyon 5(5): e01564. https://doi.org/10.1016/j.heliyon. 2019. e01564.

6. Ozsezen, A. N.; Canakci, M. 2011. Determination of performance and combustion characteristics of a diesel engine fueled with canola and waste palm oil methyl esters, Energy Conversion and Management 52(1): $108-116$. https://doi.org/10.1016/j.enconman.2010.06.049.

7. Raslavicius, L.; Bazaras, Z. 2009.The analysis of the motor characteristics of D-RME-E fuel blend during on-field tests, Transport 24(3): 187-191.

8. Song, J.; Cheenkachorn, K.; Wang, J.; Perez, J.; Boehman, A. L.; Young, P. J. 2002. Effect of oxygenated fuel on combustion and emissions in a light-duty turbo diesel engine, Energy Fuel 16(2): 294-301.

9. Liaquat, A. M.; Masjuki, H. H.; Kalam, M. A.; Fattah, I. M. R.; Hazrat, M. A.; Varman, M.; Shahabuddin, M. 2013. Effect of Coconut Biodiesel Blended Fuels on Engine Performance and Emission Characteristics, Procedia Engineering 56: 583-590.

10. Gnanasekaran, S.; Saravanan, N.; Ilangkumaran, M. 2016. Influence of injection timing on performance, emission and combustion characteristics of a DI diesel engine running on fish oil biodiesel, Energy, 116: 1218-1229.

https://doi.org/10.1016/j.energy.2016.10.039.

11. Azeem, M. W.; Hanif, M. A.; Al-Sabahi, J. N.; Khan, A. A.; Naz, S.; Ijaz, A. 2016. Production of biodiesel from low priced, renewable and abundant date seed oil, Renewable Energy 86: 124-132. https://doi.org/10.1016/j.renene.2015.08.006.

12. Raslavicius, L.; Felneris, M.; Pukalskas, S.; Rimkus, A.; Melaika, M. 2019. Evaluation of P. moriformis oil and its blends with diesel fuel as promising contributors to transportation energy, Energy 189: 116196.

13. Shanmughasundaram, P.; Gopinath, V.; Suresh, P. 2017. Performance and emission characteristics of a diesel engine runs with corn oil biodiesel blends and air pre-heater, Mechanika 23(3): 462-468.

14. Dinesh, S.; Metin Kok. 2018. A review on different parameters affecting the vehicle emission gases of different fuel mode operations, Research Journal of Science and Engineering Systems 3(4): 146-164.

15. Raslavicius, L.; Bazaras, Z. 2010. The possibility of increasing the quantity of oxygenates in fuel blends with no diesel engine modifications, Transport 25 (1): 81-88.

16. Roy, S.; Parsi, P. K.; Kotha, R. S.; Barman, S.; Vinayak, K.; Mitra Roy, M.; Banerjee, R. 2019. Effective utilisation of waste cooking oil in a single cylinder diesel engine using alumina nano particles, Sustainable Energy \& Fuels.

https://doi.org/10.1039/c9se00393b.
17. Gurz, M.; Baltacioglu, E.; Hames, Y.; Kaya, K. 2017. The meeting of hydrogen and automotive: A review, International Journal of Hydrogen Energy 42(36): 23334-23346. https://doi.org/10.1016/j.ijhydene.2017.02.124.

18. Miyamoto, T.; Hasegawa, H.; Mikami, M.; Kojima N.; Kabashima, H.; Urata, Y. 2011. Effect of hydrogen addition to intake gas on combustion and exhaust emission characteristics of a diesel engine, International Journal of Hydrogen Energy 36(20): 13138-13149. https://doi.org/10.1016/j.ijhydene.2011.06.144.

19. Aydin, K.; Kenanoglu, R. 2018. Effects of hydrogenation of fossil fuels with hydrogen and hydroxy gas on performance and emissions of internal combustion engines, International Journal of Hydrogen Energy 43(30): 14047-14058.

20. Yilmaz, A. C.; Uludamar, E.; Aydin, K. 2010. Effect of hydroxy (HHO) gas addition on performance and exhaust emissions in compression ignition engines. International Journal of Hydrogen Energy 35(20): 1136611372. https://doi.org/10.1016/j.ijhydene.2010.07.040.

21. Kundu, A.; Gil, J. H.; Jang, J. H.; Lee, H. R.; Jung, C.R.; Ku, B. S.; Chae, K. S. 2010. Room temperature hydrogen production from water in auto-electrolytic process, International Journal of Hydrogen Energy 35(20): 10827-10832.

22. Koten, H. 2018. Hydrogen effects on the diesel engine performance and emissions. International Journal of Hydrogen Energy 43(22): 10511-10519. https://doi.org/10.1016/j.ijhydene.2018.04.146

23. Liu, S.; Wang, Z.; Li, X. X.; Zhao, Y.; Li, R. N. 2016. Effects on emissions of a diesel engine with premixed HHO, RSC Advances 6(28): 23383-23389. https://doi.org/10.1039/c5ra27761b.

24. Yang, Z.; Chu, C.; Wang, L.; Huang, Y. 2015. Effects of $\mathrm{H} 2$ addition on combustion and exhaust emissions in a diesel engine, Fuel 139: 190-197. https://doi.org/10.1016/j.fuel.2014.08.057.

25. Patil, N. N.; Chavan, C. B.; More, A. S.; Baskar, P.; 2017. Generation of oxy-hydrogen gas and its effect on performance of spark ignition engine. IOP Conference Series: Materials Science and Engineering 263: 062036. https://doi.org/10.1088/1757-899x/263/6/062036.

26. Khan, H. M.; Ali, C. H.; Iqbal, T.; Yasin, S.; Sulaiman, M.; Mahmood, H.; Mu, B. 2018. Current scenario and potential of biodiesel production from waste cooking oil in Pakistan: An overview, Chinese Journal of Chemical Engineering. https://doi.org/10.1016/j.cjche.2018.12.010.

27. Corsini, A.; Di Antonio, R.; Di Nucci, G.; Marchegiani, A.; Rispoli, F.; Venturini, P. 2016. Performance analysis of a common-rail diesel engine fuelled with different blends of waste cooking oil and gasoil, Energy Procedia 101: 606-613.

28. Zareh, P.; Zare, A. A.; Ghobadian, B. 2017. Comparative assessment of performance and emission characteristics of castor, coconut and waste cooking-based biodiesel as fuel in a diesel engine, Energy 139: 883894.

29. Holman, J. P. 2012. Experimental methods for engineers. McGraw-Hill, NewYork. Eighth Edition ISBN 978-0-07-352930-1. 
30. Nikhil Aniruddha Bhave; Mahendra M. Gupta; Sandeep S. Joshi. Effect of Brown's gas addition on combustion and emissions of homogeneous charge compression ignition engine, Energy Sources, Part A: Recovery, Utilization, and Environmental Effects https://doi.org/10.1080/15567036.2020.1817194.

31. Changwei Ji; Shuofeng Wang. 2009. Effect of hydrogen addition on combustion and emissions performance of a spark ignition gasoline engine at lean conditions, international journal of hydrogen energy 34: 78237834.

32. El-Kassaby, M. M.; Eldrainy, Y. A.; Khidr, M. E. 2016. Effect of hydroxy (HHO) gas addition on gasoline engine performance and emissions, Alexandria Engineering Journal 55(1): 243-251.

33.Swain, M. R.; Yusuf, M. J.; Dulger, Z. 1993. The effect of hydrogen addition on natural gas engine operation, SAE paper No. 932775.

34. Chauhan, B. S.; Kumar, N.; Cho, H. M. A. 2012. Study on the performance and emission of a diesel engine fuelled with Jatropha biodiesel oil and its blends, Energy 37: 616-622.

35. Liu, S.; Wang, Z.; Li, X. X.; Zhao, Y.; Li, R. N. 2016. Effects on emissions of a diesel engine with premixed HHO. RSC Adv 6: 23383-23389, https://doi.org/10.1039/c5ra27761b.

36. Thangaraj, S.; Govindan, N. 2018. Investigating the pros and cons of browns gas and varying EGR on combustion, performance, and emission characteristics of diesel engine. Environ SciPollut Control Ser25(1): $422 \mathrm{e} 35$.

37. Sharma, P. K.; Sharma D.; Soni, S. L.; Jhalani, A.; Singh, D.; Sharma, S. 2020. Energy, exergy, and emission analysis of a hydroxyl fueled compression ignition engine under dual fuel mode. Fuel 265: 116923. https://doi.org/10.1016/j.fuel.2019.116923.

38. Rimkus, A.; Matijosius, J.; Bogdevicius, M.; Bereczky, A.; Torok, A. 2018. An investigation of the effi- ciency of using $\mathrm{O} 2$ and $\mathrm{H} 2$ (hydrooxile gas - $\mathrm{HHO}$ ) gas additives in a $\mathrm{CI}$ engine operating on diesel fuel and biodiesel, Energy 152: 640-651.

G. Sekar, J. Ganesh Murali, P. Shanmughasundaram

INFLUENCE OF HHO GAS ADDITION ON
COMBUSTION, PERFORMANCE AND EMISSION
CHARACTERISTICS OF A CI ENGINE FUELLED
WITH USED COOKING OIL BIO FUEL BLENDS

S u m m a r y

The present study is to investigate the influence of used cooking oil (UCO) bio diesel blend and HHO gas on combustion, performance and emission characteristics of a variable compression ratio multi fuel engine. Bio fuel is extracted from UCO through transesterification process. Blends of diesel and UCO bio fuel is used as primary fuel and hydroxyl (HHO) gas which was generated from the electrolysis of water is used as supplementary fuel. Engine was tested for three different fuels such as diesel, B20 blend and $\mathrm{B} 20+\mathrm{HHO}$ blends by varying four different loads $(25 \%, 50 \%, 75 \%$, and $100 \%)$ at the constant speed of $1500 \mathrm{rpm}$. HHO gas was injected in to the intake manifold with constant flow rate of $0.5 \mathrm{lpm}$ for all engine loads. Engine fuelled with B20+HHO blends showed better brake thermal efficiency and lower brake specific fuel consumption and emitted less $\mathrm{CO}, \mathrm{HC}$ and smoke emission over the B20 blends and diesel.

Keywords: CI engine used cooking oil bio fuel, hydroxyl gas, engine performance, emission.

Received July 22, 2020

Accepted August 07, 2021 